\title{
Editorial
}

\section{La ganadería: un mal necesario}

\author{
Omar Camargo MVZ, MSC. PhD. CVLAC
}

Editorialista invitado

Director Área Curricular Producción Agraria Sostenible

Facultad de Ciencias Agrarias

Universidad Nacional de Colombia sede Medellín

Comparte "La ganadería es un mal necesario", frase que, aunque pasó a la historia como una anotación de Antoine Lavoisier en su memoria De la richesse territoriale du royaume de France, presentada ante la Asamblea Nacional Constituyente en 1791, correspondía al sentir general de los agricultores franceses de la época.

La economía rural y la seguridad alimentaria francesas de finales del siglo XVIII, conservando la inercia medieval, seguían girando en torno a la producción de cereales. La ganadería era una actividad marginal, superflua y en ese sentido, no mayormente aportante a la economía familiar; sin embargo, al no existir aun los fertilizantes químicos, los cerealeros se veían obligados a tener animales, a sacrificar espacio valioso de sus pequeñas parcelas para destinarlo al mantenimiento y cuidado de los mismos. Todo por el estiércol.

El estiércol proporcionado por los animales de granja constituía entonces el único medio de fertilización. Sin embargo, estaba disponible en cantidades demasiado bajas como para asegurar el mantenimiento de la fertilidad. La tierra, agotada por la continuidad de los cultivos sin la restitución adecuada, y por lo demás mal trabajada, sólo daba rendimientos miserables de tres o cuatro veces la semilla, en promedio, es decir, de cuatro a ocho quintales de trigo dependiendo de las regiones y los años. De no abonarse el suelo, indefectiblemente sobrevendría el barbecho. Dejar descansar la tierra cultivada por un periodo de uno o varios años a fin de que recuperase parte de la fertilidad original, era una práctica obligada que empezó a hacerse habitual en la Europa de la edad media. Durante el barbecho se sometía el terreno a algunas prácticas culturales, entre ellas el arado, a fin de ir acondicionando la estructura física del terreno para su próximo uso y de paso eliminar e incorporar al mismo suelo, como abono, el material vegetal indeseable que sobre él creciese, buscando devolverle su fertilidad original.

Los agricultores se mostraban renuentes a reducir el área de cultivo para concedérsela a los animales y terminaban acondicionándoles el menor espacio posible, lo cual conducía indefectiblemente a la obtención de insuficiente estiércol y, en consecuencia, a bajos rendimientos en la cosecha y, finalmente, al barbecho. En resumen, no animales, no estiércol, no cereal, barbecho.

¿Qué espacio destinarle a los animales con el fin de obtener las cantidades necesarias de estiércol? Responder a esta pregunta implicó comenzar a hacer algunos cálculos lo más precisos posibles que condujeran al resultado esperado: reducir al mínimo el área a "sacrificar" sin afectar negativamente los rendimientos del cultivo. Este ejercicio paciente, reiterado y plagado de avances y retrocesos condujo a que de las entrañas de agricultura, y arrancada de allí por la Revolución Industrial, naciera la ganadería moderna. La invención de los fertilizantes químicos y la revolución forrajera, advenidas con la revolución industrial, dieron origen a la ganadería moderna hace tan sólo un poco más de 150 años. 
Esos tiempos quedaron atrás. Hoy, los bovinos ya no son un medio, son un fin. Criamos bovinos para tomar su leche, sacrificarlos y comerlos. El mundo consume alrededor de 60 millones de toneladas de carne bovina anualmente. Ya poco nos interesa su estiércol. Los productos de origen animal, en general, contribuyen hoy con el $17 \%$ del consumo de kilocalorías y el 33\% del consumo de proteínas de la población mundial, y lo seguirán haciendo. Para ello se dispone de alrededor de un $26 \%$ de la superficie total del planeta en praderas, lo que representa el $80 \%$ del suelo agrícolamente productivo, y de una fuerza laboral de alrededor de 1300 millones de personas (cerca del $20 \%$ de la población mundial actual).

Sin embargo, ¿qué tanta área "sacrificar" de nuestra aldea global para los animales?, nos preguntábamos entonces, y nos preguntamos ahora. ¿Qué tanta tierra?, ¿Qué tanta agua?, ¿Podemos evitar la competencia entre producir alimentos para humanos y producir alimentos para animales? ¿Podemos hacer un uso más eficiente de los pastizales actuales? ¿Podemos producir más en un menor espacio, sin contaminar más, sin afectar el bienestar animal, ni la calidad y la inocuidad de los productos producidos?

Me temo que responder hoy a estas preguntas, a diferencia de hace 200 años, requerirá más de conciencia que de ciencia. 